\title{
PERSPECTIVE Safeguarding the microbial water quality from source to tap
}

\author{
Jorien Favere $\mathbb{D}^{1,2,4}$, Raquel G. Barbosa ${ }^{1,3,4}$, Tom Sleutels $\mathbb{D}^{3}$, Willy Verstraete ${ }^{1}$, Bart De Gusseme $e^{1,2}$ and Nico Boon $\mathbb{D}^{1,2 凶}$
}

Anthropogenic activities and climate change can deteriorate the freshwater quality and stress its availability. This stress can, in turn, have an impact on the biostability of drinking water. Up to now, the microbiological quality of drinking water has been maintained through the selection of high-quality water sources allied to the use of disinfectants and the removal of organic carbon. But as freshwater becomes richer in other nutrients, strategies used so far may not suffice to keep a steady and high-quality supply of drinking water in the future. This article readdresses the discussion on drinking water biostability. We need to reframe the concept as a dynamic equilibrium that considers the available nutrients and energy sources (potential for growth) relative to the abundance and composition of the bacterial community (potential to consume the available resources).

npj Clean Water (2021)4:28; https://doi.org/10.1038/s41545-021-00118-1

\section{INTRODUCTION}

One of the major challenges of the drinking water sector is to guarantee the microbial safety and quality of the drinking water ${ }^{1}$. Ideally, high-quality surface- or groundwater is collected and subjected to a variety of physical, chemical, and biological treatment steps, depending on the source water quality ${ }^{2}$. Regardless of the applied treatment train, the aim remains the same. Namely, to inactivate pathogenic microorganisms, to remove chemical contaminations and organics, and to improve the esthetic characteristics of the water. However, low levels of microorganisms and organics persist in the treated water, and as a result of biochemical and physical interactions during distribution, drinking water may contain between $10^{3}$ and $10^{6}$ cells $/ \mathrm{mL}$ at the $\operatorname{tap}^{3}$. While the majority of these naturally present microorganisms does not compromise the safety of the water for human consumption, their regrowth may result in the deterioration of the water quality, such as deviating odor and taste ${ }^{4}$, and lead to technical problems ${ }^{5,6}$. In general, microbial regrowth in the drinking water distribution systems (DWDS) highly depends on the treatment applied to the source water but also on the source water quality.

Over the last decades, Europe has made substantial progress to improve the quality of freshwater bodies. The removal of phosphate from laundry detergents ${ }^{7}$, the improvements in wastewater treatment and the reductions in the agricultural use of nitrogen and phosphorus ${ }^{8}$ contributed significantly to control nutrient loading to waterbodies. Yet, despite the progress achieved, $75 \%$ of the European waterbodies remain at ecological risk $^{9}$. In addition to water pollution, there is increasing evidence that climate change will affect water supply and demand ${ }^{10}$. This will be translated into more intense and longer droughts in some regions and excessive precipitation in others ${ }^{11,12}$. Those events, in turn, enhance the risk of decreased volumes of freshwater resources for the coming decades ${ }^{13}$ and contribute to further freshwater degradation.

For the time being, the impact of nutrient pollution and groundwater scarcity may seem more relevant for developing countries. Nevertheless, industrialized countries will also need to adapt to the rapidly changing conditions. With decreasing freshwater resources, nutrient-rich freshwater waterbodies ${ }^{14}$ and greywater $^{15-17}$ will need to be (re)used more frequently for drinking water production to ensure the drinking water supply. This might pose a point of attention in the near future, as the increase in the concentration of nutrients in the raw water may subsequently increase the nutrient concentration in the drinking water, resulting in the potential regrowth of opportunistic pathogens, overall regrowth, and further biofilm development in the DWDS. This extensive regrowth may in turn exacerbate the already challenging problems found in the DWDS, such as clogging $^{6}$ and corrosion ${ }^{5}$, and changes in esthetic features ${ }^{4}$. Also, increasing temperatures have already been linked to changes in water quality, either by promoting planktonic regrowth or accelerating biofilm development ${ }^{18,19}$. Opportunistic pathogens, including indicator organisms, have also been documented to occur at higher temperatures ${ }^{20,21}$. In a scenario of climate change, where bulk water temperatures and nutrient concentrations are higher, the potential for regrowth is, therefore, also expected to increase. In addition, the current prospects include increased occurrences (and duration) of flooding events. During periods of heavy rainfall, contamination between sewage and drinking water pipes (particularly where water infrastructure is old), sewage overflow, or bypass into local waterways is also possible ${ }^{22}$.

To circumvent external contamination and control naturally present microbial (re)growth, residual disinfectants such as free chlorine and chloramine are commonly added before distribution. Those approaches are being challenged as the use of free chlorine may induce the formation of by-products that can be a toxic nuisance to humans ${ }^{23}$, and the use of chloramine may promote the development of nitrifying bacteria ${ }^{5}$. The latter oxidize the ammonia to nitrite and subsequently to nitrate. However, both compounds can become toxic for humans ${ }^{23}$. In addition, some byproducts can also cause a deviating odor and taste (e.g., trichloroanisoles) ${ }^{24}$. This forms a driving factor for drinking water utilities to avoid chlorination. In this context, water utilities tend to strive more for biostability, which implies producing microbially safe drinking water without the use of a disinfection residual ${ }^{25}$, as already applied in different European countries such as Switzerland, the Netherlands, and Germany ${ }^{26-29}$.

When producing biostable water, microbial growth is controlled by one or more disinfection strategies such as membrane filtration

\footnotetext{
${ }^{1}$ Center for Microbial Ecology and Technology (CMET), Ghent University, Gent, Belgium. ${ }^{2}$ Centre for Advanced Process Technology for Urban Resource Recovery (CAPTURE), Gent, Belgium. ${ }^{3}$ Wetsus, European Centre of Excellence for Sustainable Water Technology, Leeuwarden, The Netherlands. ${ }^{4}$ These authors contributed equally: Jorien Favere, Raquel G. Barbosa. ${ }^{凶}$ email: nico.boon@ugent.be
} 
(e.g., reverse osmosis $(\mathrm{RO})^{30}$ ), UV irradiation, ozone or AOP. The latter is often applied in combination with extensive biological treatment such as sand filters or biological active carbon (BAC) filtration. To further avoid microbial regrowth during distribution, focus is placed on organic carbon removal. Guidelines have been proposed for assimilable organic carbon $(\mathrm{AOC},<10 \mu \mathrm{g} \mathrm{C/L}$ in nonchlorinated systems, $<100 \mu \mathrm{gC} / \mathrm{L}$ in chlorinated systems) and biodegradable dissolved organic carbon (BDOC, $<150 \mu \mathrm{g} \mathrm{C} / \mathrm{L}$ ) concentrations s $^{25,31,32}$, as this is considered to be the main limiting nutrient for microbial growth in drinking water.

While this may be true for the majority of heterotrophic bacteria, the exclusive limitation of organic carbon fails to address autotrophic bacteria. Indeed, contrary to the common assumption that organic carbon is the major problem to be addressed in practice, different studies have reported a weak correlation between $A O C$ and the growth of invasive pathogens and have instead suggested phosphate as another important limiting nutrient in surface and drinking water ${ }^{33-35}$. In addition, microbial drinking water quality is often checked by only regarding the heterotrophic bacteria (e.g., HPC at $22^{\circ} \mathrm{C}$ or $\left.37^{\circ} \mathrm{C}\right)^{36}$. However, as phosphate and ammonium accumulate in surface water ${ }^{9}$ used as a drinking water source, autotrophs may grow to unwanted extents (e.g., Sydney, Australia ${ }^{37}$ ).

To understand and control microbial growth in DWDS it is crucial to revisit the current concept of biostability. All things considered, there is a clear gap between what is already known from research and what is currently implemented in practice. There is thus a need for a framework that connects both, as a balance between complexity and feasibility with regard to future challenges that will stress the water quality and availability. We propose a new framework for redefining and managing biostability, by regarding all growth-limiting factors for microbial growth, including the energy availability, and by maximizing the ratio of the number of microorganisms present to the nutrients and energy available.

\section{REVISITING THE CONCEPT OF BIOSTABILITY}

WHO states that "water entering the DWDS must be microbially safe and ideally should also be biologically stable ${ }^{\prime \prime 36}$. Biological stability was primarily defined by Rittmann \& Snoeyink as "the inability of water or a material in contact with water to support microbial growth in the absence of a disinfectant ${ }^{\prime 38}$. However, in our opinion, one can never achieve such true biostability, as a microbial ecosystem is dynamic and always evolving, and the perception of stability is limited by the technology being used to study the ecosystem. For example, with the current scientific knowledge, it is known that even when heterotrophic plate count results are perfectly constant over time or throughout distribution, there may still be considerable changes in the microbial abundance. With the rise of direct and sensitive approaches to monitor the microbial abundance and composition in the network such as flow cytometry ${ }^{39,40}$ and sequencing methods ${ }^{41}$, the challenge has thus shifted toward defining the "degree of acceptable change". A complete overview of the current knowledge about biological stability in drinking water is given by Prest et $\mathrm{al}^{1}$. Here, we try to address all aforementioned challenges into a framework for biostability and we revisit the fundamental aspects that govern it. From our point of view, biostability implies stability of both the bacterial abundance and bacterial community composition.

To define a stable bacterial community composition, the main concept is based on microbial resource management ${ }^{42}$. This means that we aim to steer the microbial community of the water to a state that is resistant toward invasion and/or growth of unwanted microorganisms, and does not show excessive regrowth during distribution. More specifically, we are introducing the $\mathrm{r} / \mathrm{K}$-strategist concept, which has, to the best of our

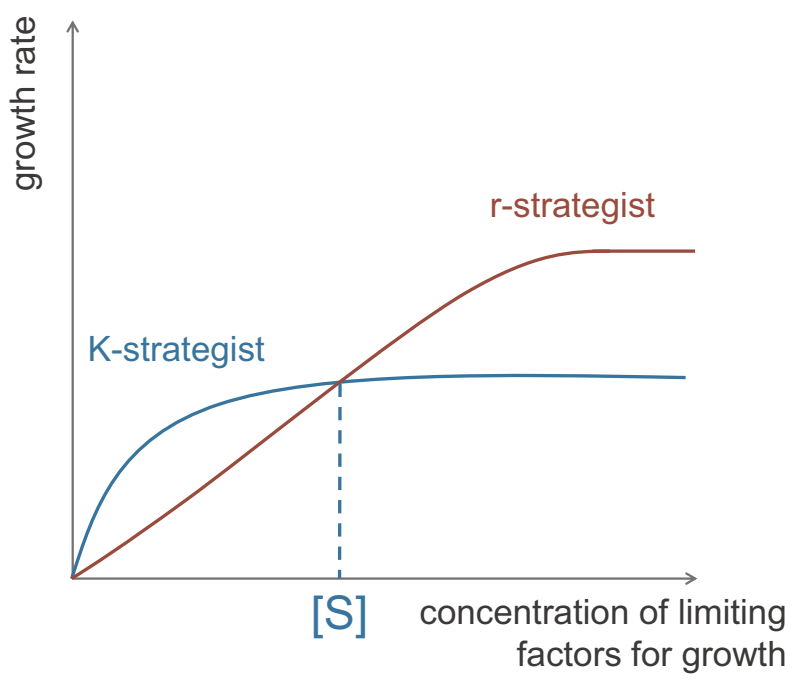

Fig. 1 Growth rate of $\mathrm{K}$ - and r-strategists in function of the concentration of growth-limiting factors. At concentrations lower than the critical K/r threshold concentration [S] (blue), K-strategists (naturally present bacteria) will dominate the community, whereas, at higher concentrations, unwanted regrowth of r-strategists (opportunistic pathogens and indicator organisms) can occur. Adapted from De Vrieze et al $^{46}$.

knowledge, not been applied to microbial drinking water ecosystems yet (Fig. 1). This concept originates from macroecology ${ }^{43}$, and has been expanded to microbial ecosystems such as aquaculture ${ }^{44}$, soil ${ }^{45}$ and anaerobic digestion ${ }^{46}$. Although it may "oversimplify" the ecosystem's dynamics, the r/K-strategist concept is preferred amongst other ecological concepts such as the resource-ratio theory ${ }^{47,48}$ or $C / S / R$ theory ${ }^{49}$ as it forms a balance between practical feasibility and complexity. Within the $\mathrm{r} / \mathrm{K}$ framework, (micro)organisms are classified as either r-strategists, characterized by a high growth rate at high nutrient concentrations, or K-strategists, characterized by a high substrate affinity. In drinking water, we consider the naturally present community to consist out of K-strategists, whereas pathogens and indicator organisms are rather classified as r-strategists, analogous to applications in aquaculture ${ }^{50}$. Using this approach, biostability can be achieved by steering the bacterial community toward K-strategists through nutrient limitation. Also, research has shown that by limiting the nutrients in the water entering the distribution network, the biological activity in both the water and biofilm will decrease and EPS production and subsequent bio-adhesion will decrease $e^{6,51,52}$. Thus, by focusing on nutrient limitation as a strategy to limit bacterial growth in the network, it is hypothesized that this approach may also limit biofilm formation.

In terms of bacterial abundance, we aim to produce water that contains a bacterial load close to the carrying capacity $(M)^{53}$ of the ecosystem, regarding all phases (e.g., bulk water, biofilm, loose deposits). The carrying capacity is widely applied in ecology and has been defined as the maximum number of individuals that a given level of nutrients and environmental conditions (niche) can support. In practice, this means that different initial densities of certain species in the same drinking water are expected to reach a certain carrying capacity, as based on the Gompertz growth curve (Supplementary Fig. 1). The carrying capacity can be influenced by a set of factors (such as availability of nutrients, space and temperature) and the interactions between them. By aiming at bacterial densities close to the carrying capacity, the energy input to the ecosystem will approximate the maintenance cost of the bacteria, and the net regrowth during distribution will be limited ${ }^{54}$. In our concept, we consider the growth-limiting factor 


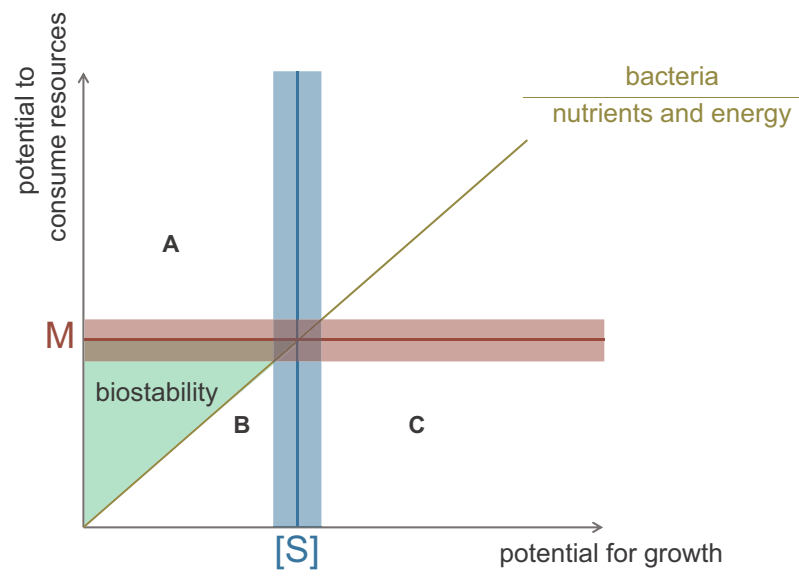

Fig. 2 The concept of biostability as a function of the potential for growth and the potential to consume resources. The potential for growth is measured as the concentration of growth-limiting factors ( $x$-axis), and the potential to consume resources is measured as the bacterial load (y-axis). At a growth-limiting factor concentration below the threshold [S] (blue vertical line), selection favours the K-strategists (see also Fig. 1). The microbial abundance should be close to the carrying capacity $\mathrm{M}$ (red horizontal line). When these two conditions are fulfilled, the relative amount of nutrients and energy available for a bacterium ("per caput") will be minimized (yellow diagonal line). Biostable water must comply with these three boundaries (green area). When a small change in bacterial or nutrient concentration occurs, a biostable ecosystem should be resilient (blue and red marked area around $M$ and [S]). Three situations of biological instability are illustrated. A A bacterial load above the carrying capacity of the ecosystem will result in die-off, resulting in a release of nutrient and (necrotrophic) growth. B A too low bacterial load will result in overall regrowth. C A growth-limiting factor concentration above the $\mathrm{K} / \mathrm{r}$ threshold concentration will result in regrowth of unwanted r-strategists.

concentrations (Fig. 2, $x$-axis) and the total bacterial abundance (Fig. 2, y-axis) as the two main determinants for biostability. The former comprises the available nutrients as well as electron donors and acceptors necessary for the bacterial energy metabolism ${ }^{27}$.

Two main conditions should be fulfilled for obtaining biostable water, regarding the total bacterial load and total growth-limiting factors concentration. First, the total nutrient and energy availability (further represented as " $\mathrm{S}$ ") should be below the threshold concentration to select for K-strategists and not induce regrowth that can lead to water quality deterioration, and in extreme cases pose health risks (e.g., regrowth of pathogens) ${ }^{55}$ (Fig. 2, point C). Secondly, the total bacterial load should be close to the carrying capacity. If this is not the case, the system becomes prone to invasion and microbial die-off will occur, and dead biomass can become available as nutrients, resulting in necrotrophic growth by pathogens such as Legionella pneumophila (Fig. 2, point $A)^{56}$. Hence, to become biostable, drinking water should contain a relatively high amount of bacteria compared to the amount of growth-limiting factors available (Fig. 2). When compliant with these conditions, biostability can be defined as a dynamic equilibrium in which a small increment of growthlimiting factors above the lower threshold $(S+\Delta S)$ leads to a density increase $(M+\Delta M)$ but falls rapidly back (to $M$ ) without bringing along major disturbances in terms of bacterial abundance and composition (Fig. 2, red and blue area, Supplementary Fig. 1, green area). As shown in Fig. 2, biostability is defined as a range determined by the boundaries explained above, wherein changes within the bacterial community structure and abundance as a response to environmental changes are allowed. For example, growth as a result of normal seasonal fluctuations is in this respect not considered as biological instability.

To implement the proposed concept of biostability in practice, and to define the "degree of acceptable change", a framework for decision-making is necessary. This implies (1) networkspecific calibration to define the desired state of stability of the microbial community, as we believe that the boundaries for biostability will depend on the ecosystem's characteristics, and (2) defining the allowed deviation from that baseline state. More specifically, we suggest the use of flow cytometry as a fast, even online, and non-targeted technique to quantitatively (microbial abundance, total cell counts) and qualitatively (microbial community structure, flow cytometric fingerprinting) assess the total microbial community's stability ${ }^{57,58}$. A baseline state can first be defined by validating the water quality using routine parameters and methods. Based on the baseline flow cytometric measurements, a threshold can be set on the total cell counts and change in fingerprint (e.g., mean plus three times the standard deviation) ${ }^{39,59}$. To account for progressive changes such as normal seasonal changes, the use of a dynamic baseline calculated by for example moving window analysis (MWA) ${ }^{60,61}$ or moving endpoint analysis (MEA) ${ }^{62}$ is proposed. In this regard, the total microbial community, here monitored using flow cytometry, serves as an indicator for the microbial water quality. When deviations from the baseline occur, targeted approaches such as selective plating, $\mathrm{qPCR}$, or third-generation sequencing can be used to further define if this deviation was related to the proliferation of pathogens. Overall, this framework relies on the development of a dynamic and network-specific threshold, as the degree of acceptable change will depend on the drinking water network and its location, water source, and infrastructure in specific. Hence, it is difficult to impose general guidelines for bacterial abundance or community structure. For example, up to date, there are no general straightforward thresholds or upper limits in the European Drinking Water Directive 98/83/EC ${ }^{63}$ regarding the total bacterial abundance. This is different compared to bottled water, where an upper limit of e.g., 100 $\mathrm{CFU} / \mathrm{mL}$ at $22{ }^{\circ} \mathrm{C}$ is defined. The proposed framework may thus serve as an addition and guidance to the conventional methods for evaluating the microbial water quality as required by the regional/national law.

\section{ACHIEVING HIGH-QUALITY SOURCE WATER}

Both the source water quality and the water treatment are crucial for the production of biostable drinking water. Eutrophication of surface waters (in)directly stands as one of the major threats to the water biostability. One of the most visible signs of excessive nutrient inputs in surface waters are cyanobacterial blooms. Apart from food web alterations and loss of diversity, large blooms often lead to an increase in water turbidity, foul smells and clogging ${ }^{64}$. Furthermore, drinking water productions often face the additional challenge of removing toxins produced by cyanobacteria.

Taking into account the prospects for increasing and extended eutrophication events, it is critical to develop and establish sustainable technologies capable of removing nutrients from surface waters to the microgram/L level, while maintaining an ecologically friendly status. Popular methods such as constructed wetlands $^{65}$, artificial floating islands ${ }^{66}$, ecological floating beds $s^{67}$, gravel-packed contact beds ${ }^{68}$ and pre-dams ${ }^{69}$, which rely on the growth rate of plants and demand large areas of land, will most often not be adequate or operationally affordable. Precipitation as well as adsorption strategies, on the other hand, have obtained very promising results. Both Phoslock, a lanthanum modified bentonite that removes soluble phosphorus by forming lanthanum phosphate precipitates ${ }^{70}$, and adsorptive materials ${ }^{71}$ can remove soluble phosphorus to levels below $10 \mu \mathrm{g} / \mathrm{L}$. A drawback, however, is that both technologies, only target one 
specific nutrient. Surface waters receiving nutrients from agricultural runoff often exhibit high levels of phosphorus as well as nitrogen. Hence, a combination of methods targeting different nutrients is required to maintain microbial quality regarding all growth-limiting factors. The latter concept is applied in the field of food technology, where the microbial stability and safety is based on a combination of several factors (hurdles) that should not be overcome by the microorganisms present $^{72}$. Alternatively, biological strategies consider the limitation of different available growth-limiting factors and are therefore a promising route for obtaining a good ecological status of surface waters. One recently available example is the use of the autotrophic hydrogen oxidizing bacteria to treat eutrophic water ${ }^{73}$. The use of a highly energetic electron donor allows for the combined removal of nutrients such as phosphorus and nitrogen down to levels below $10 \mu \mathrm{g} / \mathrm{L}$. Another example is the self-sustaining in situ photo-microbial nutrients recovery cell, which allows for the removal and recovery of nutrients with simultaneous electricity generation and microalgae production ${ }^{74}$. In this way, excessive microbial growth can be minimized resulting in a high-quality water source for subsequent drinking water production.

\section{BIOSTABILITY DURING DRINKING WATER TREATMENT AND DISTRIBUTION}

Drinking water treatment consists of different steps, which can impact the biostability of the final drinking water by changing the water characteristics in one or more ways ${ }^{1}$. Even though the drinking water exiting the production utilities is most often of high quality, microbial regrowth may still occur during distribution of biologically unstable drinking water ${ }^{64}$. Most regrowth is observed when using surface water as a source as on the one hand, the nutrient concentrations are higher compared to groundwater, and are not always sufficiently removed to avoid further regrowth during distribution ${ }^{3}$. On the other hand, surface waters are sometimes subject to extreme seasonal fluctuations, e.g., a higher water temperature in summer resulting in more regrowth ${ }^{39,75,76}$. To anticipate the increasing stress imposed on the water quality and supply by climate change and population growth, the drinking water quality at the exit of the production utility must be biostable as defined in the proposed framework, to avoid problems at the tap.

One interesting approach to remove nutrients and microorganisms to ultra-low levels at the end of the treatment train is $\mathrm{RO}$. RO is an emerging technology that physically retains bacteria and nutrients by pushing the water molecules over a membrane under high pressure. This technology is also applied for desalination of brackish water or seawater, with retention efficiencies up to $99.5 \%{ }^{77}$, and performs even better when preceded by complementary technologies such as ion exchange ${ }^{78}$. Yet, because the concentration of microorganisms is low relative to the growth-limiting factors in the filtrate, the produced water is not always biostable as there are plenty of niches available for microbial growth during the subsequent distribution. Regarding the proposed framework, this means that even though the concentrations are low in absolute amounts, the nutrients and energy available per caput is high, allowing for regrowth during distribution (Fig. 2, point B). For example, bacterial growth in RO permeate showed a 2 log increase in a lab-scale setup tested by Park \& $\mathrm{Hu}^{79}$.

Biofiltration (e.g., activated carbon filtration) is often applied after physicochemical treatment to avoid regrowth in the distribution network and to remove trace pollutants ${ }^{80}$. This treatment step is crucial for obtaining biostable drinking water, as nutrients will be removed by a combination of adsorption and controlled microbial growth on the filter. Furthermore, the microbial community on the filter can have an impact on the composition of the microbial community of the distribution network $^{81}$ (Fig. 2, point A). Also, biofiltration allows the production of "microbially matured water" as used in aquaculture, by seeding the drinking water with a harmless naturally present microbial community that is occupying all niches in densities close to the carrying capacity of the water, hereby favoring the growth of K-strategists (Fig. 1). This way, this diverse microbial community controlling all growth opportunities, will be less prone to pathogen invasion and environmental stress. In addition, by changing the composition and concentration of growth-limiting factors (nutrients or electron donors/acceptors), the microbial community in the filter and the produced drinking water (through seeding) could be steered toward a desired composition or its functionality can be optimized to capture nutrients selectively or to an overall larger extent. With regard to the future, it is important to note that the water quality of the source will affect the performance of the biofilter, as a high nutrient loading may result in clogging or incomplete removal. Hence, striving for biostability of the final drinking water includes optimizing both the preceding multi-barrier treatment and the biofiltration process itself.

After biofiltration, residual disinfection is sometimes applied to suppress microbial growth during distribution. However, this approach is detrimental to achieving biostability, as useful microbial cells controlling the nutrients will be killed and the ratio of active microbial cells over all bioavailable nutrients lowers. Moreover, dead biomass will serve as a substrate for necrotrophic regrowth in the distribution network ${ }^{42}$. As regrowth in drinking water during distribution is almost unavoidable ${ }^{82}$, the production of biostable water through extensive steering and control of growth-limiting factors is preferred over the use of a disinfection residual as it is a more sustainable and safer (e.g., absence of disinfection-by-products) approach. Nevertheless, proper maintenance of the DWDS, clever engineering (e.g., to avoid longer HRTs) and high-resolution monitoring of the microbial dynamics becomes even more important to ensure the microbial water quality at the $\operatorname{tap}^{39,40,83}$.

\section{OUTLOOK}

Creating biostable water is the way forward for controlling the microbial water quality in drinking water from the source to tap, and in industrial process- or cooling waters. We need to focus on the things we can control, such as the concentration of growthlimiting factors and microorganisms entering the distribution network. In this respect, we should particularly deal with the ratio of K-strategist microorganisms over the amount of available nutrients and energy sources. That ratio must be sufficiently high to prevent overall (re)growth and growth of unwanted r-strategist pathogens in particular. In this respect, it is important to regard the effect of not only the quantity but also the composition of limiting nutrients, such as for example different carbon fractions, on the biostability of the drinking water. Also, more research is needed in understanding the relation between the planktonic community, operational conditions and the detachment of unwanted species from the biofilm, to avoid discomfort (e.g., odor or taste problems) or water quality issues at the tap. In practice, interventions in terms of nutrient removal should take place as early as possible in the water treatment chain to avoid problems downstream. Also, high-resolution monitoring and understanding of microbial (re)growth in production processes and the DWDS remain of utmost importance to ensure the microbial water quality at all times.

\section{DATA AVAILABILITY}

Data sharing not applicable to this article as no datasets were generated or analyzed during the current study. 
Received: 11 December 2020; Accepted: 26 March 2021; Published online: 27 April 2021

\section{REFERENCES}

1. Prest, E. I., Hammes, F., van Loosdrecht, M. C. M. \& Vrouwenvelder, J. S. Biological stability of drinking water: controlling factors, methods, and challenges. Front. Microbiol. 7, 45 (2016).

2. de Moel, P. J., Verberk, J. Q. J. C. \& van Dijk, J. C. Drinking water: Principles and practices. Drinking water: Principles and practices. (World Scientific Publishing Co., 2006). https://doi.org/10.1142/6135.

3. Nescerecka, A., Rubulis, J., Vital, M., Juhna, T. \& Hammes, F. Biological instability in a chlorinated drinking water distribution network. PLOS ONE 9, e96354 (2014).

4. Skjevrak, I., Lund, V., Ormerod, K., Due, A. \& Herikstad, H. Biofilm in water pipelines; a potential source for off-flavours in the drinking water. Water Sci. Technol. 49, 211-217 (2004)

5. Zhang, Y., Love, N. \& Edwards, M. Nitrification in drinking water systems. Crit. Rev. Envi Sci. Tech. 39, 153-208 (2009).

6. Liu, S. et al. Understanding, monitoring, and controlling biofilm growth in drinking water distribution systems. Environ. Sci. Technol. 50, 8954-8976 (2016).

7. Litke, D. W. Review of phosphorus control measures in the United States and their effects on water quality. U.S. Geological Survey Water-Resources Investigations Report 99-4007. http://pubs.usgs.gov/wri/wri994007/pdf/wri99-4007.pdf (1999).

8. EC. Directive 2000/60/EC of the European Parliament and of the Council of 23 October 2000 establishing a framework for Community action in the field of water policy. OJEC https://doi.org/10.1039/ap9842100196 (2000).

9. European Environmental Agency. European waters Assessment of status and pressures 2018. https://www.eea.europa.eu/publications/state-of-water (2018).

10. Konapala, G., Mishra, A. K., Wada, Y. \& Mann, M. E. Climate Change will affect global water availability through compounding changes in seasonal precipitation and evaporation. Nat. Commun. 11, 3044 (2020).

11. Grillakis, M. G. Increase in severe and extreme soil moisture droughts for Europe under climate change. Sci. Total Environ. 660, 1245-1255 (2019).

12. Myhre, G. et al. Frequency of extreme precipitation increases extensively with event rareness under global warming. Sci. Rep. 9, 012131 (2019).

13. Richey, A. S. et al. Quantifying renewable groundwater stress with GRACE. Water Resour. Res. 51, 5217-5237 (2015)

14. Lace, I., Krauklis, K., Spalvinš, A. \& Laicans, J. Implementations of Riga city water supply system founded on groundwater sources. IOP Conf. Ser. Mater. Sci. Eng. 251, 012131 (2017).

15. Oron, G. et al. Greywater use in Israel and worldwide: standards and prospects. Water Res. 58, 92-101 (2014).

16. Lahnsteiner, J. \& Lempert, G. Water management in Windhoek, Namibia. Water Sci. Technol. 55, 441-448 (2007)

17. Vandenbohede, A., Houtte, E. Van \& Lebbe, L. Water quality changes in the dunes of the western Belgian coastal plain due to artificial recharge of tertiary treated wastewater. Appl. Geochem. 24, 370-382 (2009).

18. Fish, K. E., Osborn, A. M. \& Boxall, J. Characterising and understanding the impact of microbial biofilms and the extracellular polymeric substance (EPS) matrix in drinking water distribution systems. Environ. Sci. Water Res. Technol. 2, 614-630 (2016).

19. Flemming, H. C. \& Wingender, J. The biofilm matrix. Nat. Rev. Microbiol. 8 623-633 (2010).

20. Tsao, H. F. et al. The cooling tower water microbiota: Seasonal dynamics and cooccurrence of bacterial and protist phylotypes. Water Res. 159, 464-479 (2019).

21. van der Wielen, P. W. J. J. \& van der Kooij, D. Nontuberculous mycobacteria, fungi, and opportunistic pathogens in unchlorinated drinking water in the Netherlands. Appl. Environ. Microbiol. 79, 825-834 (2013).

22. Cann, K. F., Thomas, D. R., Salmon, R. L., Wyn-Jones, A. P. \& Kay, D. Extreme waterrelated weather events and waterborne disease. Epidemiol. Infect. 141, 671-686 (2013).

23. Sedlak, D. L. \& Von Gunten, U. The chlorine dilemma. Science 331, 42-43 (2011).

24. Nystrom, A., Grimvall, A., Krantz-Rulcker, C., Savenhed, R. \& Akerstrand, K. Drinking water off-flavour caused by 2,4,6-trichloroanisole. Water Sci. Technol. 25, 241-249 (1992).

25. van der Kooij, D. Assimilable organic carbon as an indicator of bacterial regrowth. J. Am. Water Work. Assoc. 84, 57-65 (1992).

26. Rosario-Ortiz, F., Rose, J., Speight, V., Gunten, U. V. \& Schnoor, J. How do you like your tap water? Science 351, 912-914 (2016).

27. Hammes, F., Berger, C., Köster, O. \& Egli, T. Assessing biological stability of drinking water without disinfectant residuals in a full-scale water supply system. J. Water Supply Res. T 59, 31-40 (2010).

28. Baghoth, S. A., Dignum, M., Grefte, A., Kroesbergen, J. \& Amy, G. L. Characterization of NOM in a drinking water treatment process train with no disinfectant residual. Water Sci. Tech.-W. Sup 9, 379-386 (2009).
29. Hambsch, B. Distributing groundwater without a disinfectant residual. J. Am Water Work. Assoc. 91, 81-85 (1999).

30. Sousi, M. et al. Measuring Bacterial Growth Potential of Ultra-Low Nutrient Drinking Water Produced by Reverse Osmosis: Effect of Sample Pre-treatment and Bacterial Inoculum. Front. Microbiol. 11, 791 (2020).

31. Lechevallier, M. W., Welch, N. J. \& Smith, D. B. Full-scale studies of factors related to coliform regrowth in drinking water. Appl. Environ. Microbiol. 62, 2201-2211 (1996).

32. Servais, P., Barillier, A. \& Garnier, J. Determination of the biodegradable fraction of dissolved and particulate organic carbon in waters. Ann. Limnol. - Int. J. Lim 31 75-80 (1995).

33. Van Nevel, S., De Roy, K. \& Boon, N. Bacterial invasion potential in water is determined by nutrient availability and the indigenous community. FEMS Microbiol. Ecol. 85, 593-603 (2013).

34. Vital, M., Stucki, D., Egli, T. \& Hammes, F. Evaluating the growth potential of pathogenic bacteria in water. Appl. Environ. Microbiol. 76, 6477-6484 (2010).

35. Lehtola, M. J., Miettinen, I. T., Vartiainen, T., Myllykangas, T. \& Martikainen, P. J. Microbially available organic carbon, phosphorus, and microbial growth in ozonated drinking water. Water Res. 35, 1635-1640 (2001).

36. WHO. Guidelines for drinking-water quality, 4th edition, incorporating the 1st addendum. (World Health Organization, 2017).

37. Sathasivan, A., Fisher, I. \& Tam, T. Onset of severe nitrification in mildly nitrifying chloraminated bulk waters and its relation to biostability. Water Res. 42 3623-3632 (2008).

38. Rittmann, B. E. \& Snoeyink, V. L. Achieving biologically stable drinking water. J. Am. Water Work. Assoc. 76, 106-110 (1984).

39. Favere, J., Buysschaert, B., Boon, N. \& De Gusseme, B. Online microbial fingerprinting for quality management of drinking water: Full-scale event detection. Water Res. 170, 115353 (2020).

40. Prest, E. I., Hammes, F., Kötzsch, S., van Loosdrecht, M. C. M. \& Vrouwenvelder, J. S. Monitoring microbiological changes in drinking water systems using a fast and reproducible flow cytometric method. Water Res. 47, 7131-7142 (2013).

41. Prest, E. I. et al. Combining flow cytometry and $16 \mathrm{~S}$ rRNA gene pyrosequencing: a promising approach for drinking water monitoring and characterization. Water Res. 63, 179-189 (2014).

42. Chatzigiannidou, I., Props, R. \& Boon, N. Drinking water bacterial communities exhibit specific and selective necrotrophic growth. npj Clean Water 1, 22 (2018).

43. MacArthur, R. H. \& Wilson, E. O. The Theory of Island biogeography (MPB-1). (Princeton University Press, 2015).

44. De Schryver, P. \& Vadstein, O. Ecological theory as a foundation to control pathogenic invasion in aquaculture. ISME J. 8, 2360-2368 (2014).

45. Brzeszcz, J., Steliga, T., Kapusta, P., Turkiewicz, A. \& Kaszycki, P. r-strategist versus $\mathrm{K}$-strategist for the application in bioremediation of hydrocarbon-contaminated soils. T Biodeterior. Biodegrad. Int. Biodeter. 106, 41-52 (2016).

46. De Vrieze, J., Christiaens, M. E. R. \& Verstraete, W. The microbiome as engineering tool: manufacturing and trading between microorganisms. N. Biotechnol. 39, 206-214 (2017)

47. Tilman, D. Resources: a Graphical-Mechanistic Approach to Competition and Predation. Am. Nat. 116, 362-393 (1980).

48. Jia, M., Winkler, M. K. H. \& Volcke, E. I. P. Elucidating the Competition between Heterotrophic Denitrification and DNRA Using the Resource-Ratio Theory. Environ. Sci. Technol. 54, 13953-13962 (2020).

49. Ho, A. et al. Conceptualizing functional traits and ecological characteristics of methane-oxidizing bacteria as life strategies. Environ. Microbiol. Rep. 5, 335-345 (2013).

50. Vadstein, O., Attramadal, K. J. K., Bakke, I. \& Olsen, Y. K-selection as microbial community management strategy: a method for improved viability of larvae in aquaculture. Front. Microbiol. 9, 1-17 (2018)

51. Liu, G., Verberk, J. Q. J. C. \& Van Dijk, J. C. Bacteriology of drinking water distribution systems: an integral and multidimensional review. Appl. Microbiol. Biotechnol. 97, 9265-9276 (2013).

52. Lehtola, M. J., Miettinen, I. T. \& Martikainen, P. J. Biofilm formation in drinking water affected by low concentrations of phosphorus. Can. J. Microbiol. 48 494-499 (2002).

53. Odum, E. P. \& Barrett, G. W. Fundamentals of Ecology. Third Edition. Thomson, Brooks/Cole (W.B. Saunders Co., 1971).

54. Andrews, J. H. \& Harris, R. F. r- and K-Selection and Microbial Ecology. Advances in Microbial Ecology (Springer, Boston, MA, 1986). https://doi.org/10.1007/978-14757-0611-6 3.

55. O'Neil, J. M., Davis, T. W., Burford, M. A. \& Gobler, C. J. The rise of harmful cyanobacteria blooms: the potential roles of eutrophication and climate change. Harmful Algae 14, 313-334 (2012).

56. Temmerman, R., Vervaeren, H., Noseda, B., Boon, N. \& Verstraete, W. Necrotrophic growth of Legionella pneumophila. Appl. Environ. Microbiol. 72, 4323-4328 (2006). 
57. Besmer, M. D. et al. Laboratory-scale simulation and real-time tracking of a microbial contamination event and subsequent shock-chlorination in drinking water. Front. Microbiol. 8, 1900 (2017).

58. Props, R., Monsieurs, P., Mysara, M., Clement, L. \& Boon, N. Measuring the biodiversity of microbial communities by flow cytometry. Methods Ecol. Evol. 7, 1376e1385 (2016).

59. Howell, D., Rogier, M., Yzerbyt, V. \& Bestgen, Y. Méthodes statistiques en sciences humaines. (De Boeck Université, 1998).

60. Marzorati, M., Wittebolle, L., Boon, N., Daffonchio, D. \& Verstraete, W. How to get more out of molecular fingerprints: Practical tools for microbial ecology. Environ. Microbiol. 10, 1571-1581 (2008).

61. Wittebolle, L. et al. Failure of the ammonia oxidation process in two pharmaceutical wastewater treatment plants is linked to shifts in the bacterial communities. J. Appl. Microbiol. 99, 997-1066 (2005).

62. Boon, N., Pycke, B. F. G., Marzorati, M. \& Hammes, F. Nutrient gradients in a granular activated carbon biofilter drives bacterial community organization and dynamics. Water Res. 45, 6355-6361 (2011).

63. European Union. $98 / 83 / E C$ on the quality of water intented for human consumption. OJEC 41, 32-54 (1998).

64. Liu, G. et al. Potential impacts of changing supply-water quality on drinking water distribution: a review. Water Res. 116, 135-148 (2017).

65. White, S. A. \& Cousins, M. M. Floating treatment wetland aided remediation of nitrogen and phosphorus from simulated stormwater runoff. Ecol. Eng. 127, 468-479 (2013).

66. Chang, N. Bin, Islam, K., Marimon, Z. \& Wanielista, M. P. Assessing biological and chemical signatures related to nutrient removal by floating islands in stormwater mesocosms. Chemosphere 88, 736-743 (2012).

67. Wu, Q., Hu, Y., Li, S., Peng, S. \& Zhao, H. Microbial mechanisms of using enhanced ecological floating beds for eutrophic water improvement. Bioresour. Technol. 211, 451-456 (2016).

68. Lin, J. L., Tu, Y. T., Chiang, P. C., Chen, S. H. \& Kao, C. M. Using aerated gravelpacked contact bed and constructed wetland system for polluted river water purification: a case study in Taiwan. J. Hydrol. 525, 400-408 (2015).

69. Benndorf, J. \& Pütz, K. Control of eutrophication of lakes and reservoirs by means of pre-dams-I. Mode of operation and calculation of the nutrient elimination capacity. Water Res. 21, 829-838 (1987).

70. Haghseresht, F., Wang, S. \& Do, D. D. A novel lanthanum-modified bentonite, Phoslock, for phosphate removal from wastewaters. Appl. Clay Sci. 46, 369-375 (2009).

71. Kumar, P., Korving, L., van Loosdrecht, M. C. M. \& Witkamp, G. J. Adsorption as a technology to achieve ultra-low concentrations of phosphate: Research gaps and economic analysis. Water Res. X 4, 100029 (2019).

72. Leistner, L. Basic aspects of food preservation by hurdle technology. Int. J. Food Microbiol. 55, 181-186 (2000).

73. Barbosa, R. G., Sleutels, T., Verstraete, W. \& Boon, N. Hydrogen oxidizing bacteria are capable of removing orthophosphate to ultra-low concentrations in a fed batch reactor configuration. Bioresour. Technol. 311, 123494 (2020).

74. Jiang, Q., Song, X., Liu, J., Shao, Y. \& Feng, Y. Enhanced nutrients enrichment and removal from eutrophic water using a self-sustaining in situ photomicrobial nutrients recovery cell (PNRC). Water Res. 167, 115097 (2019).

75. Nescerecka, A., Juhna, T. \& Hammes, F. Identifying the underlying causes of biological instability in a full-scale drinking water supply system. Water Res. 135, 11-21 (2018).

76. Pinto, A. J., Schroeder, J., Lunn, M., Sloan, W. \& Raskin, L. Spatial-temporal survey and occupancy-abundance modeling to predict bacterial community dynamics in the drinking water microbiomez. mBio 5, e01135-14 (2014).

77. Fritzmann, C., Löwenberg, J., Wintgens, T. \& Melin, T. State-of-the-art of reverse osmosis desalination. Desalination 216, 1-76 (2007)

78. Grefte, A., Dignum, M., Baghoth, S. A., Cornelissen, E. R. \& Rietveld, L. C. Improving the biological stability of drinking water by ion exchange. Water Sci. Tech.-W Sup. 11, 107-112 (2011).

79. Park, S. K. \& Hu, J. Y. Assessment of the extent of bacterial growth in reverse osmosis system for improving drinking water quality. J. Environ. Sci. Health A. 45, 968-977 (2010).

80. Kirisits, M. J., Emelko, M. B. \& Pinto, A. J. Applying biotechnology for drinking water biofiltration: advancing science and practice. Curr. Opin. Biotechnol. 57, 197-204 (2019).
81. Pinto, A. J., Xi, C. \& Raskin, L. Bacterial community structure in the drinking water microbiome is governed by filtration processes. Environ. Sci. Technol. 46, 8851-8859 (2012)

82. Douterelo, I., Husband, S., Loza, V. \& Boxall, J. Dynamics of biofilm regrowth in drinking water distribution systems. Appl. Environ. Microbiol. 82, 4155-4168 (2016).

83. Van Nevel, S. et al. Flow cytometric bacterial cell counts challenge conventional heterotrophic plate counts for routine microbiological drinking water monitoring. Water Res. 113, 191-206 (2017).

\section{ACKNOWLEDGEMENTS}

This work was performed in the cooperation framework of Wetsus, European Centre of excellence for sustainable water technology (www.wetsus.nl). Wetsus is co-funded by the Dutch Ministry of Economic Affairs and Ministry of Infrastructure and Environment, the European Union Regional Development Fund, the Province of Fryslân and the Northern Netherlands Provinces. This work has received funding from the European Union's Horizon 2020 research and innovation program under the Marie Skłodowska-Curie [665874], the Geconcentreerde Onderzoeksactie, Ghent University [BOF15/GOA/006], the FWO Flanders [3S85419] and the FWO-SBO Biostable Project [S006221N]. The authors would like to thank the research theme 'Protein from Water', for the fruitful discussions and financial support.

\section{AUTHOR CONTRIBUTIONS}

Conceptualization: J.F., R.B., T.S., B.D.G. and N.B. Funding acquisition: N.B., B.D.G., W.V. and T.S. Writing-original draft: J.F. and R.B. Writing-review and editing: J.F., R.B., T.S., W.V., B.D.G. and N.B.

\section{COMPETING INTERESTS}

The authors declare that they have no known competing financial interests or personal relationships that could have appeared to influence the work reported in this paper.

\section{ADDITIONAL INFORMATION}

Supplementary information The online version contains supplementary material available at https://doi.org/10.1038/s41545-021-00118-1.

Correspondence and requests for materials should be addressed to N.B.

Reprints and permission information is available at http://www.nature.com/ reprints

Publisher's note Springer Nature remains neutral with regard to jurisdictional claims in published maps and institutional affiliations.

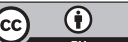

Open Access This article is licensed under a Creative Commons Attribution 4.0 International License, which permits use, sharing, adaptation, distribution and reproduction in any medium or format, as long as you give appropriate credit to the original author(s) and the source, provide a link to the Creative Commons license, and indicate if changes were made. The images or other third party material in this article are included in the article's Creative Commons license, unless indicated otherwise in a credit line to the material. If material is not included in the article's Creative Commons license and your intended use is not permitted by statutory regulation or exceeds the permitted use, you will need to obtain permission directly from the copyright holder. To view a copy of this license, visit http://creativecommons. org/licenses/by/4.0/.

(c) The Author(s) 2021 